\title{
Práticas interdisciplinares nos anos iniciais do Ensino Fundamental: um estudo de teses e dissertações
}

\author{
Interdisciplinary practice in the Early Years of School: a study of theses \\ and dissertations
}

Marilac Luzia de Souza Leite Sousa Nogueira ${ }^{1}$

Jorge Megid Neto ${ }^{1}$

\section{Resumo}

Este artigo é resultado de uma pesquisa que se propôs a analisar práticas escolares interdisciplinares desenvolvidas nas séries iniciais do ensino fundamental, tratadas em teses e dissertações brasileiras, com a intenção de elucidar práticas pedagógicas diferenciadas da convencional. Foram analisadas pesquisas compreendidas entre os anos de 1987 a 2005, identificadas a partir do Banco de Teses da CAPES. Obteve-se um total de 2.503 trabalhos, dentre os quais 489 trataram de temas voltados para a educação escolar. Com base na leitura dos resumos, identificamos 49 pesquisas que abrangeram a primeira fase do ensino fundamental e, destas, apenas 14 abrangeram práticas pluridisciplinares ou interdisciplinares. Estas foram analisadas com base nos seguintes descritores: instituição, ano de defesa, grau acadêmico, série escolar, disciplinas abrangidas, métodos e estratégias de ensino, nível de integração curricular, recursos e materiais didáticos, referencial metodológico de ensino, público envolvido e tipo de interação entre ele, nível de integração disciplinar (multidisciplinar, pluridisciplinar ou interdisciplinar), o que nos possibilitou oferecer um panorama crítico-analítico das pesquisas que tratam da questão interdisciplinar nesse nível de escolaridade.

Palavras-chave: prática pedagógica; interdisciplinaridade, anos iniciais do ensino fundamental, estado da arte.

\begin{abstract}
This paper describes and analyzes interdisciplinary school practices, developed in initial series of elementary level and mentioned in theses and dissertations defended in Brazil. The data was taken from the eletronic bank of CAPES through the following key-words: interdisciplinary, interdisciplinary practices, "multidisciplinary" and "polydisciplinary". Due to the availability of data offered on the consulted basis the covered period was between 1987 to 2005. A total of 2503 works was found and among them 489 developed themes directed to scholarly education. Starting from this universe, and based on the summary readings, 49 researches which covered the initial period of elementary school teaching were identified. Fourteen of these researches approached interdisciplinary pedagogical practices, in the sense characterized in our theoretical references, specially Hilton Japiassu. These researches were described and analyzed based on the following descriptions: institution, year of defending, academic degree, scholar grade, subjects covered, teaching strategies, level of curriculum integrations, resources and pedagogical material, teaching method references, people involved and kind of interaction among them, level of teaching organization (interdisciplinary, multidisciplinary or polydisciplinary).
\end{abstract}

Keywords: pedagogical practice, interdisciplinary, elementary school, state of the art.

\footnotetext{
${ }^{1}$ Universidade Estadual de Campinas, São Paulo - UNICAMP
} 


\section{Introdução}

As discussões sobre interdisciplinaridade surgem no Brasil no final da década de 1960 e início de 1970, decorrentes do esforço em responder questões emergentes no âmbito da produção e divulgação dos conhecimentos científicos, bem como dos processos educacionais em geral, na busca por um entendimento sistêmico e holístico da manifestação dos fenômenos, sejam eles da ordem das ciências ou da educação em geral.

Ao estudar a História do Conhecimento da Civilização Ocidental, observamos que a concepção de conhecimento como uma unidade é anterior ao século XVII (ZOBÓLI, 1992). Para os sofistas gregos, todo saber racional era considerado Filosofia (Matemática, Pedagogia, Física, Biologia, Astronomia, Lógica, Ética). Na Idade Média, o conjunto unitário de conhecimentos era reunido em Trivium (Gramática, Retórica e Dialética) e Quadrivium (Aritmética, Geometria, Astronomia, Música). No Renascimento, Francis Bacon propunha a criação de um centro de pesquisas interdisciplinares e Comenius, no século XVII, a Pansophia, saber unificado que buscava relacionar vários conhecimentos.

O século XIX se caracteriza pelas ideias positivas que enaltecem a observação e o raciocínio, e que têm como contribuição o pensamento de Descartes: "[...] dividir cada dificuldade a ser examinada em tantas partes quanto possível para resolvê-las [...]" (DESCARTES, 1975, p.27). Nessa perspectiva, o homem conseguiria produzir um conhecimento isento de contaminação dos sentidos humanos, sendo seu resultado legitimado pela autoridade da razão.

Os princípios da razão cartesiana contribuem significativamente para o avanço da Ciência Moderna, o que promove um terreno fértil para a produção científica num panorama analítico, distinto e muito claro, por meio de um processo de decomposição lógica do objeto a ser estudado. Desse modo, cada vez mais são especificados os vários campos de conhecimento, decorrendo um grande número de especializações com metodologias específicas, teorias e sistemas para cada disciplina, o que trouxe certo distanciamento das demais áreas de conhecimento.

Para Japiassu (1976), essa divisão da ciência em múltiplas especialidades acaba por produzir um "estado patológico" do conhecimento, caracterizado pela hermeticidade e excessiva especialização. Esse contexto de produção científica traz a falsa ideia de que os fenômenos em estudo são considerados de forma desconectada dos problemas da vida, tendo a ciência existência e fim em si mesma.

Em contraposição à hermetização dos campos científicos, a perspectiva interdisciplinar propõe o inter-relacionamento das especialidades para a compreensão dos fenômenos a serem estudados, na intenção de contribuir para uma dimensão mais unificada e totalizante da ciência e do homem.

Semelhante ao que ocorre na ciência, o currículo escolar se organiza em disciplinas (atividades de ensino) como, por exemplo: Ciências Naturais, Matemática, Língua Portuguesa entre outras, reproduzindo de certo modo o que ocorre nas especialidades da ciência. No ambiente escolar, essa disposição curricular geralmente reforça que se ofereça ao estudante um contato parcelar e compartimentado com as diferentes áreas de conhecimento.

Nesse modo de ensinar, em que as matérias escolares são apresentadas aos estudantes em alvéolos disciplinares, o que se mostra ao aluno são partes do conhecimento, sem a necessária preocupação de tratar a articulação das várias áreas de conhecimento. Isto 
contribui para um distanciamento da escola com o movimento da vida, nas suas dimensões sociais, econômicas e culturais.

Esse fato tende a desencadear um ensino voltado para a compartimentação dos conteúdos na sua abordagem em sala de aula, o que distancia o aluno da sua vivência e de uma melhor compreensão de si e da realidade que o cerca, dificultando a ampliação de condições de entendimento e posicionamento dos problemas vitais e sociais, cujos conteúdos são trabalhados em sala de aula em contornos bem delimitados e herméticos.

$\mathrm{Na}$ área educacional, a proposta interdisciplinar traz uma reação alternativa para a abordagem monodisciplinar normalizada dos currículos, declarando a necessidade de interconexões disciplinares que permitam uma relação contextualizada, articulada entre as diferentes disciplinas, os problemas reais e o contexto social vivido pelo estudante. A abordagem interdisciplinar traz consigo a visão de um sujeito que se sinta uno na composição do universo, que seja ativo na autoria da sua própria história de vida, ultrapassando e ampliando a compreensão pluridimensional do mundo, propondo um caminho novo para a existência de uma escola diferente da que temos nas últimas décadas (FAZENDA, 1995).

Em suma, essa proposta de superação da compartimentação das várias áreas de ensino surge impregnada do esforço de superação de um modelo histórico construído sob as bases da abstração, refletidas no currículo escolar e nos atuais modelos de ensino. A recomposição do saber delimitado pelas partes é função do interdisciplinar, o qual se propõe a uni-las para recompor o todo, de modo que ele seja conhecido e compreensível, transcendendo os limites territoriais impostos pela necessidade do desenvolvimento disciplinar.

\section{Modalidades de Interdisciplinaridade}

A noção de interdisciplinaridade varia quanto aos termos e conceitos utilizados por vários autores. Iremos aqui considerar três autores que apresentam significações de interdisciplinaridade, com diferentes nuanças, distinguindo seus níveis. Optamos por Hilton Japiassu (1976), Jean Piaget (1972) e Heinz Heckhaussen (2006), por entendermos que oferecem uma gama de significações do termo interdisciplinaridade e termos correlatos, favorecendo a melhor compreensão de suas variações e semelhanças.

Iniciaremos pela definição de disciplinaridade segundo Japiassu (1976). Para o autor, o conceito refere-se à exploração científica especializada numa certa área ou domínio homogêneo de estudo. A disciplina é designada como uma ciência, como uma atividade de pesquisa e também para significar o "ensino" de uma ciência.

Para o autor, se se pretende ter clareza do que trata o interdisciplinar é necessário situar de um lado o multi e o pluridisciplinar, por se tratarem de categorias de pouca ou nenhuma colaboração entre si, e, de outro, o interdisciplinar e o transdisciplinar que pressupõem a colaboração entre as disciplinas e interdisciplinas.

A multidisciplinaridade designa, para Japiassu (1976), um trabalho em que as disciplinas se apresentam de forma justaposta, sem necessariamente se envolverem de modo coordenado num trabalho integrado de várias disciplinas. Ou seja, essas vão se desenvolvendo de forma isolada sem que haja qualquer tipo de articulação entre elas. Cada disciplina se desenvolve de maneira estanque, sem ultrapassar seus limites fronteiriços, não havendo intenção de estabelecer relações com outras disciplinas. 
O termo pluridisciplinaridade trata de um nível de pouca colaboração disciplinar. Caracteriza-se pela justaposição de diversas disciplinas, havendo certo grau de cooperação entre elas, embora cada disciplina mantenha objetivos distintos. Nesse caso, as disciplinas que fornecem informação atuam como colaboradoras a outra disciplina, sem que haja interrelação direta, estabelecendo uma relação de dependência ou subordinação. Por exemplo, Ciências Naturais estabelece relação colaborativa com História, mas História não estabelece relação colaborativa com Ciências Naturais. Assemelham-se a esse tipo de ação certos trabalhos escolares desenvolvidos por professores de diferentes disciplinas, que colaboram com seus respectivos conhecimentos para auxiliar no estudo e compreensão de um determinado problema central, não ultrapassando o limite da mera colaboração e não estabelecendo, portanto, um intercâmbio disciplinar entre ambas que decorra em cooperação mútua.

Deve-se destacar que, na conceituação de Japiassu (1976), o termo "pluridisciplinaridade" corresponde à noção que a grande maioria dos professores da educação básica e pesquisadores atribuem ao conceito de "multidisciplinaridade". Por exemplo, é frequente ouvirmos professores dizerem que realizaram um projeto ou estudo multidisciplinar com seus alunos, querendo significar que desenvolveram um trabalho integrado. Ou ainda, no âmbito acadêmico, ouvirmos três ou quatro grupos de pesquisa dizerem que estão desenvolvendo um projeto multidisciplinar, querendo informar que os grupos reúnem suas diferentes especialidades de maneira colaborativa. Na visão de Japiassu (1976), estes dois exemplos compreendem estudos "pluridisciplinares" e não "multidisciplinares". Para o autor, multidisciplinar implica fragmentação, compartimentação, isolacionismo, independência. Pluridisciplinar supõe também especialização e fragmentação, mas implica algum nível - tênue que seja - de articulação e colaboração entre as disciplinas ou áreas de conhecimento.

Quanto à interdisciplinaridade, Japiassu (1976, p.73) a concebe como "axiomática comum a um grupo de disciplinas conexas e definidas no nível hierárquico imediatamente superior, o que introduz a noção de finalidade". Nesse nível, há uma relação direta entre as disciplinas, caracterizada por um sistema de dois níveis coordenados pelo nível superior, e pela cooperação entre as mesmas. Isso equivale, na escola, a uma ação de ensinoaprendizagem em que, diante de um determinado fenômeno ou problema a ser estudado, duas ou mais disciplinas colaboram entre si com um propósito único, transpondo seus limites territoriais. Nesse projeto educativo, não há supremacia entre as disciplinas, mas uma ação coletiva e colaborativa de conhecimentos direcionados para um único objetivo.

A transdisciplinaridade é considerada por esse autor como o último grau da interdisciplinaridade, identificado pela "coordenação de todas as disciplinas e interdisciplinas do sistema de ensino inovado, sobre a base de uma axiomática geral" (1976, p.74). Nesse estágio encontramos níveis e objetivos múltiplos e há uma finalidade comum entre os sistemas com coordenação entre si. Todas as disciplinas envolvidas estabelecem colaboração entre si, apresentando cooperação mútua. Esse estágio é o último da interdisciplinaridade se consideradas de forma ascendente as relações estabelecidas pelas disciplinas através de sua gradação.

A interdisciplinaridade também é considerada de forma ascendente por Jean Piaget (1972), iniciando pela multidisciplinaridade, estágio inferior de integração, no qual há ajuda de outras disciplinas, porém, sem que necessariamente se configure enriquecimento mútuo. O estágio seguinte é denominado pelo autor de interdisciplinaridade. Nele se configura a existência de troca e enriquecimento mútuo entre as disciplinas o qual é seguido pelo 
terceiro e último estágio, a transdisciplinaridade, em que as disciplinas se dispõem a construir um sistema total composto por elas, sem que as fronteiras disciplinares apresentem resistência.

Note-se que o termo "multidisciplinaridade" em Piaget (1972) tem sentido semelhante ao conceito de "pluridisciplinaridade" em Japiassu (1976). A perspectiva de Piaget coincide com o uso mais frequente que professores e pesquisadores fazem do termo "multidisciplinaridade" nos trabalhos escolares e acadêmicos. Piaget não considera o termo pluridisciplinaridade.

$\mathrm{Na}$ perspectiva de Heckhaussen (2006), a interdisciplinaridade se coloca em ordem ascendente a partir da "disciplinaridade", sendo seguida pela "interdisciplinaridade heterogênea" e "pseudo-interdisciplinaridade", dois termos que designam uma forma mais elaborada de pluridisciplinaridade para o autor, em que as disciplinas permutam informações, sem que haja trocas entre si. Trata-se de uma relação de dependência e ou subordinação em que as disciplinas se caracterizam como auxiliares.

Heckhaussen (2006) nos apresenta quatro últimos termos, os quais denomina de "interdisciplinaridade auxiliar", "interdisciplinaridade compósita", "interdisciplinaridade complementar" e "interdisciplinaridade unificadora", indicando a existência de trocas recíprocas de forma ascendente entre essas gradações, não havendo supremacia entre as disciplinas. Considera que o enriquecimento entre elas chega a seu grau máximo na "interdisciplinaridade unificadora", a qual possibilita a origem de novas disciplinas (ou interdisciplinas, na visão de Japiassu, 1976) como, por exemplo, a psicossociologia, a biofísica, a bioquímica entre outras.

Acrescentamos ao panorama apresentado que os vários pesquisadores da temática interdisciplinar não limitam suas discussões ao modo técnico-metodológico, mas acrescentam nessa pauta a atitude em favor da unidade e compreensividade da existência humana, em conjunto com a colaboração das concorrências disciplinares (colaborações e intercâmbios recíprocos), o que exige dos pesquisadores certo desprendimento e anonimato.

No espaço escolar, o trabalho interdisciplinar propõe que os professores dialoguem entre si, que não haja supremacia entre as disciplinas e que os estudos dos conteúdos curriculares ocorram de forma inter-relacionada, partindo das diversas contribuições disciplinares. Na relação professor-aluno, a interdisciplinaridade convoca esses atores para fazerem do processo de aquisição do conhecimento algo ligado às necessidades da vida cotidiana e do mundo social, valorizando os conteúdos assimilados pelos alunos fora da escola. Nessa perspectiva, o ambiente escolar se transforma num lugar instigante à busca de conhecimentos que promovam a autonomia intelectual e a atitude democrática.

\section{Procedimentos de Pesquisa}

$\mathrm{Na}$ intenção de conhecer a produção acadêmica brasileira sobre as práticas interdisciplinaridades realizadas nos anos iniciais do ensino fundamental e na busca por compreender e contribuir para sua divulgação, desenvolvemos um estudo do tipo estado da arte.

Esse modelo de estudo, também chamado de pesquisa do estado atual do conhecimento (SOARES, 1989), é caracterizado por descrever, analisar e avaliar de forma sistemática o que se tem produzido em determinada área. A realização dessas pesquisas implica na identificação, seleção, classificação e descrição de trabalhos de certa área do 
conhecimento, com a finalidade de atender os objetivos do pesquisador, bem como de exercer a análise e avaliação dos principais resultados, contribuições e lacunas identificadas no material analisado, de modo a contribuir de forma criteriosa para o desenvolvimento de determinada área de conhecimento (MEGID NETO, 1999).

Como fontes de dados iniciais, os pesquisadores que adotam esse método de pesquisa podem se reportar, segundo Ferreira (2002), aos catálogos de faculdades, institutos, universidades, associações nacionais e órgãos de fomento à pesquisa. Outra fonte de dados, apontada por Teixeira e Megid Neto (2006), são os periódicos e comunicações apresentadas em eventos acadêmico-científicos.

Iniciamos nosso levantamento de dados junto aos documentos disponibilizados no Banco de Teses da Coordenação de Aperfeiçoamento de Pessoal de Nível Superior (CAPES), consultado em setembro de 2005. O período abrangido foi de 1987, ano de defesa das primeiras teses e dissertações inseridas nesse banco de dados, até 2005.

Norteados pelas palavras-chave: interdisciplinar; práticas interdisciplinares; interdisciplinaridade; multidisciplinar; e pluridisciplinar, obtivemos um total de 2.503 trabalhos, conforme distribuição indicada na Tabela 1.

TABELA 1 - Teses e Dissertações Referentes ao Tema Interdisciplinaridade Identificadas pelo Banco de Teses e Dissertações da CAPES (1987 a 2005)

\begin{tabular}{|c|c|c|c|}
\hline & $\begin{array}{c}\text { Palavras-Chave de } \\
\text { Busca }\end{array}$ & $\begin{array}{c}\text { Total de } \\
\text { Documentos Obtidos }\end{array}$ & Observações \\
\hline A & Interdisciplinar & 1460 & \\
\hline$B$ & $\begin{array}{c}\text { Práticas } \\
\text { Interdisciplinares }\end{array}$ & 0 & $\begin{array}{c}\text { obtidas 487, todas contidas } \\
\text { em A }\end{array}$ \\
\hline C & Interdisciplinaridade & 330 & $\begin{array}{c}\text { obtidas 489, } 159 \text { contidas em } \\
\text { A }\end{array}$ \\
\hline D & Multidisciplinar & 703 & $\begin{array}{c}\text { obtidas } 737,24 \text { contidas em } \\
\text { A, 10, contidas em C }\end{array}$ \\
\hline \multirow[t]{2}{*}{$E$} & Pluridisciplinar & 10 & \\
\hline & Total Geral & 2503 & \\
\hline
\end{tabular}

Fonte: Banco eletrônico de Teses e Dissertações da CAPES

(http://www.periodicos.capes.gov.br/portugues/index.jsp), acesso em 26/9/2005.

Todos os trabalhos obtidos foram considerados, independentemente de se tratarem ou não de assuntos relativos ao ensino escolar ou à educação, ou seja, os dados coletados foram integralmente considerados. Por exemplo, no conjunto de 2.503 trabalhos encontram-se pesquisas sobre arquitetura, ciências sociais, enfermagem, entre outras. Não fizemos o descarte inicial desses trabalhos apenas pela leitura dos respectivos títulos, pois algumas pesquisas poderiam ter alguma relação com educação escolar. Também não fizemos o descarte para poder analisar o percentual de participação das pesquisas voltadas para a educação escolar e também das pesquisas sobre práticas interdisciplinares no universo das teses e dissertações que dizem tratar da questão interdisciplinar.

De posse desses dados, passamos à fase seguinte, em que realizamos a classificação dos trabalhos localizados pelos assuntos relacionados à Educação Escolar ou a Temas Não Educacionais ou Não Escolares, através da leitura dos 2.503 resumos encontrados. Como 
resultado, obtivemos 489 documentos que tratam da Educação Escolar e 2.014 trabalhos que se dedicaram a Temas Não Educacionais ou Não Escolares.

Nessa fase da pesquisa notamos que quase $20 \%$ das teses e dissertações referentes ao foco temático interdisciplinaridade são destinadas a pesquisas no universo educacional escolar. Em contraposição, pouco mais de $80 \%$ se direcionam a outras áreas de conhecimento não diretamente relacionadas ao campo educacional escolar, como Arquitetura, Medicina, Direito entre outras.

Este foi um primeiro resultado deste estudo bastante inesperado: 4/5 das pesquisas que se voltam para a abordagem de questões relativas à interdisciplinaridade não tratam de temas da educação ou não se voltam para a escola em seus diversos níveis, muito embora a educação escolar seja um espaço de grande importância para desenvolvimento e formação dos indivíduos e para a transmissão dos conhecimentos produzidos pela humanidade.

Ao mesmo tempo em que líamos e classificávamos a totalidade dos resumos obtidos, também selecionamos o nível escolar envolvido pelos trabalhos, já que nossa pesquisa se debruça sobre as práticas pedagógicas interdisciplinares nos anos iniciais do ensino fundamental.

A Tabela 2 apresenta esse momento do trabalho. Traz em destaque os dados referentes a teses e dissertações voltadas para a Educação Escolar, num total de 489 trabalhos do universo de 2.503 pesquisas. Dos estudos de Educação Escolar, separamos aqueles voltados para os quatro primeiros anos do ensino fundamental, obtendo apenas 51 trabalhos (2,0\% do universo de pesquisas); e dentre esse subconjunto, separamos aqueles que descrevem Práticas Pedagógicas no âmbito das teses ou dissertações, restando 21 documentos.

TABELA 2 - Distribuição das 2.503 Teses e Dissertações sobre Interdisciplinaridade por Educação Escolar, Anos Iniciais do Ensino Fundamental (EF 1) e Práticas Pedagógicas nos Anos Iniciais

\begin{tabular}{ccc}
\hline TEMÁTICA da PESQUISA & No $^{\circ}$ de DOCUMENTOS & FREQÜÊNCIA \\
\hline Trabalhos Interdisciplinares & 2503 & $100,0 \%$ \\
Educação Escolar & 489 & $19,5 \%$ \\
Anos Iniciais do Ens. Fundamental & 51 & $2,0 \%$ \\
Práticas Pedagógicas em EF 1 & 21 & $0,9 \%$ \\
\hline
\end{tabular}

Fonte: Banco de Dados da CAPES, (http://www.periodicos.capes.gov.br/portugues/index.jsp), acesso em 26/9/2005

Esse momento da pesquisa nos fez notar que a quantidade de trabalhos relacionados à prática pedagógica interdisciplinar nos anos iniciais do ensino fundamental é da ordem de apenas 0,9\%, em relação ao total de 2.503 trabalhos, e 4,5\% em relação aos 489 trabalhos que se referem à Educação Escolar. Este foi um segundo resultado inesperado do levantamento de dados que realizamos.

Esta situação causou-nos muita surpresa, já que os anos iniciais do ensino fundamental constituem um terreno bastante fértil para atividades interdisciplinares, pois geralmente há um único professor para cada turma de alunos e o tempo destinado às disciplinas fica a cargo deste professor.

Outro indicador que nos chama a atenção é que, num período de 18 anos do levantamento, encontramos a reduzida quantidade de 21 pesquisas que trataram de práticas interdisciplinares nos anos iniciais do ensino fundamental, o que significa 1,2 pesquisa/ano direcionada para esse tema. 
Deve-se pensar seriamente sobre tal escassez, se considerarmos a necessidade de uma compreensão integrada dos conhecimentos construídos pelo homem, a importância dessa fase de escolaridade e de desenvolvimento da criança, bem como o imperativo que se impõe ao entendimento das ciências atreladas à vida/vivência das crianças, a qual não acontece de forma compartimentada ou em áreas de conhecimento estanques.

Por fim, fomos à busca dos textos completos das 21 dissertações ou teses selecionadas. Lançamos mão dos seguintes mecanismos: buscas em bancos ou bibliotecas digitais; empréstimo entre bibliotecas ou Comutação Bibliográfica (COMUT)), contato com autores via correio eletrônico. Obtivemos os textos completos de 20 trabalhos. $O$ trabalho restante não se encontrava na biblioteca depositária de origem e também não conseguimos contato com a respectiva autora por correio eletrônico, telefone ou correio. Sendo assim, esse trabalho foi excluído da análise.

Passamos à leitura dos textos completos dos 20 trabalhos e observamos que 6 deles não se caracterizavam como pesquisas sobre práticas pedagógicas, muito embora pela leitura dos respectivos resumos isso tivesse sido evidenciado. Duas dissertações tinham como foco a análise de documentos oficiais ou dos saberes de professores, não guardando uma relação direta com práticas pedagógicas escolares. Outras quatro dissertações analisavam práticas pedagógicas de professores envolvendo duas ou mais disciplinas, porém, ao final do trabalho, os respectivos autores concluíam que as práticas não tinham se caracterizado como práticas interdisciplinares. Decidimos, então, analisar as práticas pedagógicas retratadas nas restantes 14 dissertações e teses, cujas referências encontramse no Apêndice deste artigo.

\section{Análise dos dados}

Para esta fase da pesquisa, elaboramos uma ficha de análise que continha um conjunto de descritores que entendemos melhor permitir o conhecimento e compreensão dessas práticas, além de possibilitar a inferência de como são implementadas no espaço escolar.

Os descritores utilizados foram os seguintes: aspectos institucionais gerais (autor, orientador, instituição, ano de defesa, grau acadêmico); aspectos didáticos (série escolar, disciplinas abrangidas, estratégias de ensino utilizadas, recursos e materiais didáticos, público envolvido e o tipo de interação entre ele); aspectos curriculares (nível de inserção curricular, referencial teórico-metodológico, nível de integração disciplinar).

Os aspectos gerais estão apresentados abaixo no Quadro 1.

Este quadro revela que todas as pesquisas tiveram autores e orientadores distintos, o que indica não haver uma concentração de trabalhos sobre práticas pedagógicas interdisciplinares direcionados para os anos iniciais em algum grupo de pesquisa. A distribuição por instituição nos revela que houve concentração de trabalhos na região Sudeste do país (08 trabalhos), seguidas por outras regiões de menor expressão como a Nordeste (03 trabalhos), a Sul (02 trabalhos) e a Centro-Oeste com um trabalho defendido.

Quanto ao grau de titulação, identificamos 10 documentos que são dissertações de mestrado e 04 teses de doutorado e nenhum trabalho de doutorado que corresponda a um mesmo autor de mestrado.

O ano de produção das pesquisas nos revelou que o primeiro trabalho defendido foi no ano de 1991 e, a partir dessa data, observamos que em vários anos houve apenas 01 trabalho defendido, ficando a maior frequência para o ano de 2003 com 03 defesas. 
QUADRO 1: Distribuição das 14 pesquisas sobre Práticas Pluri ou Interdisciplinares por aspectos institucionais gerais

\begin{tabular}{c|l|l|l|l|c}
\hline Doc. & Autor & Orientador & Instituição & Ano & Grau \\
\hline 1 & Araujo,MCCS & Chizzotti,A & PUC-SP & 1996 & $\mathrm{M}$ \\
\hline 2 & Assunção,WL & Feltran,RCS & UFU & 1995 & $\mathrm{M}$ \\
\hline 3 & Brauna,RCA & Hosoume,Y & USP & 2000 & $\mathrm{D}$ \\
\hline 4 & Dantas, JDAS & Santiago, NV & UFRN & 2001 & $\mathrm{D}$ \\
\hline 5 & Frutuoso,MNMA & Taffarel,CNZ & UFPE & 2002 & $\mathrm{M}$ \\
\hline 6 & Going,LC & Custódio,EM & UMESP & 1994 & $\mathrm{M}$ \\
\hline 7 & Gonçalves,FS & Carvalho,DR & USP & 1995 & $\mathrm{D}$ \\
\hline 8 & Hoffman,VK & Groenwald,CLO & ULBRA & 2003 & $\mathrm{M}$ \\
\hline 9 & Lima,ML & Passini,EY & UEM & 2003 & $\mathrm{M}$ \\
\hline 10 & Mello,AM & Nicolau,MLM & USP & 1998 & $\mathrm{D}$ \\
\hline 11 & Polenz,T & Golçalves,MAS & UNISINOS & 1997 & $\mathrm{M}$ \\
\hline 12 & Santos, MJA & Barros, HF & UNESP & 1998 & $\mathrm{M}$ \\
\hline 13 & Silva,AC & Rego,RG & UFPB & 2003 & $\mathrm{M}$ \\
\hline 14 & Warschauer,C & Sipavicius,NAA & USP & 1991 & $\mathrm{M}$ \\
\hline & & Fonte Banco & &
\end{tabular}

Fonte: Banco eletrônico de Teses e Dissertações da CAPES

(http://www.periodicos.capes.gov.br/portugues/index.jsp), acesso em 26/9/2005.

O Quadro 2 apresenta os aspectos didáticos dos 14 documentos identificados:

$\mathrm{Na}$ distribuição dos documentos por ano escolar, notamos que do total das 14 pesquisas analisadas, 08 delas se referem ao $1^{\circ}$ ano e 07 envolvem alunos e situações escolares de $4^{\circ}$ ano, o que nos possibilita apontar certa tendência de realização de trabalhos nos $1^{\circ}$ e $4^{\circ}$ anos do ensino fundamental.

No que se refere às disciplinas envolvidas nas pesquisas, a maioria lidou com conteúdos de Língua Portuguesa, Matemática, Ciências, Artes/Educação Artística e Estudos Sociais, ou seja, parece que a tendência é sempre envolver um conjunto relativamente grande e diversificado de componentes curriculares nas práticas.

Os métodos e estratégias de ensino utilizados apontam para predominância de "estudo do meio" e "método de projetos", atividades que implicam trabalho coletivo de diversos professores e turmas de alunos e, no caso de projetos, ações de planejamento realizadas pelos próprios alunos. A análise dos recursos e materiais didáticos possibilitou identificar uma grande diversidade de materiais utilizados, porém nenhum com características especiais. Todos os materiais são encontrados comumente nas escolas, como lápis, tesoura, cola, régua, entre outros. Evidenciamos ainda que o "entorno da escola" (vegetação, riacho) e uso de papel (sulfite, cartolina etc.) aparecem em quase 50\% das práticas analisadas.

O descritor público envolvido e tipo de interação entre ele revela que em 10 documentos a relação estabelecida entre professores e alunos ou entre pesquisadores e alunos ocorreu de forma hierárquica e vertical. Em 07 trabalhos a relação entre 0 pesquisador e os professores e equipe técnica foi de parceria, muito embora da parte desses para com os alunos, não. Isso nos causou preocupação já que a interdisciplinaridade pressupõe a horizontalidade e participação ativa de todos os envolvidos no processo. Contudo, esse fato não impediu que em nossa análise identificássemos que os alunos participaram ativamente com bastante interesse das atividades propostas, apesar de não compartilharem do planejamento das mesmas. Notamos, ainda, que os pais, quando envolvidos, tinham participação cooperativa, apenas fornecendo materiais ou informações para as atividades pedagógicas. 
QUADRO 2 - Distribuição das 14 Pesquisas sobre Práticas Pluri ou Interdisciplinares por Aspectos Didáticos

\begin{tabular}{|c|c|c|c|c|c|}
\hline Doc & Série & Disciplinas & $\begin{array}{l}\text { Métodos e } \\
\text { Estratégias }\end{array}$ & $\begin{array}{c}\text { Recursos e } \\
\text { Materiais Didáticos }\end{array}$ & $\begin{array}{l}\text { Público Envolvido / } \\
\text { Interação }\end{array}$ \\
\hline 1 & $1^{\circ}$ & $L P, E S, M, C$ & $\begin{array}{l}\text { método silábico } \\
\text { e global }\end{array}$ & $\begin{array}{c}\text { cartilha, livro de leitura, } \\
\text { cartazes etc }\end{array}$ & $\begin{array}{c}\text { alunos,profs.(pesq.) / } \\
\text { Hierárquica }\end{array}$ \\
\hline 2 & $1^{0}-8^{\circ}$ & $\begin{array}{l}\text { todas, sem } \\
\text { especificar }\end{array}$ & Projeto & $\begin{array}{l}\text { filme, lixo reciclável, } \\
\text { entorno escolar etc }\end{array}$ & $\begin{array}{c}\text { alunos, pais, profs.,pesq./ } \\
\text { Colaborativa }\end{array}$ \\
\hline 3 & $1^{0}-3^{\circ}$ & C,EF,Art,Fon & Projeto & $\begin{array}{l}\text { textos, vídeos, desenhos, } \\
\text { dança etc }\end{array}$ & $\begin{array}{c}\text { alunos, profs., diret., estag.(pesq.) / } \\
\text { Parceria e Colaborativa } \\
\text { (prof.alunos Hierárquica) }\end{array}$ \\
\hline 4 & $3^{\circ}-4^{0}$ & $L P, M, C, E S$ & $\begin{array}{l}\text { estudo do meio/ } \\
\text { projeto }\end{array}$ & $\begin{array}{c}\text { aula passeio/entorno } \\
\text { escolar, ateliês etc }\end{array}$ & $\begin{array}{c}\text { alunos,profs.,estag.(pesq.) / } \\
\text { Parceria }\end{array}$ \\
\hline 5 & $4^{\circ}$ & $L P, M, C, A$ & estudo temático & $\begin{array}{l}\text { papel, tesoura, cola, } \\
\text { varetas, linha etc }\end{array}$ & $\begin{array}{c}\text { alunos, profs. (pesq.) / } \\
\text { Hierárquica }\end{array}$ \\
\hline 6 & $1^{\circ}$ & $L P, E S, M, C, A$ & estudo do meio & $\begin{array}{l}\text { contos de fadas, } \\
\text { revistas, jornal etc }\end{array}$ & $\begin{array}{c}\text { alunos, profs.,pesq. / } \\
\text { Hierárquica }\end{array}$ \\
\hline 7 & $1^{\circ}$ a $3^{\circ}$ & $L P, E S, C$ & estudo temático & $\begin{array}{l}\text { produção de textos, } \\
\text { ilustrações etc }\end{array}$ & $\begin{array}{c}\text { alunos, estag., pesq. / } \\
\text { Parceria }\end{array}$ \\
\hline 8 & $1^{0}-4^{0}$ & $C, A, E S, M, L P$ & estudo do meio & $\begin{array}{l}\text { entorno escolar, } \\
\text { horta caseira etc }\end{array}$ & $\begin{array}{l}\text { alunos, profs., equipe técn.,pesq. / } \\
\text { Parceria (prof.-alunos } \\
\text { Hierárquica) (pais: Cooperação) }\end{array}$ \\
\hline 9 & $1^{\circ}$ & $C, E S, L P, M, A r t, E F$ & estudo do meio & $\begin{array}{l}\text { ent.escolar, cooperativa, } \\
\text { papel, lápis de cor etc }\end{array}$ & $\begin{array}{c}\text { alunos, profs.,coordenadoras, pes } \\
\text { q./Parceria (prof.alunos } \\
\text { Hierárquica) }\end{array}$ \\
\hline 10 & $1^{\circ}$ & $E F, L P, M, E S, C$ & $\begin{array}{l}\text { ativ. corporais e } \\
\text { lúdicas }\end{array}$ & papel, bola, corda etc & $\begin{array}{c}\text { alunos, profs. / } \\
\text { Colaborativa (prof-alunos } \\
\text { Hierárq.) }\end{array}$ \\
\hline 11 & $4^{0}-5^{\circ}$ & $\begin{array}{c}\mathrm{LP}, \mathrm{Art}, \mathrm{ES}, \mathrm{M}, \mathrm{C}, \mathrm{EF}, \\
\mathrm{R}\end{array}$ & estudo temático & $\begin{array}{l}\text { ent.escolar, } \\
\text { equip.público, filmes, } \\
\text { papel etc. }\end{array}$ & $\begin{array}{c}\text { alunos, profs., diret., superv.,pesq. } \\
\text { Parceria (prof-alunos } \\
\text { Hierárquica) }\end{array}$ \\
\hline 12 & $4^{\circ}$ & $\begin{array}{c}C, E A, L P, M, E S, R, \\
A \\
\end{array}$ & Projeto & $\begin{array}{c}\text { jornal, poesias, pintura, } \\
\text { música etc }\end{array}$ & \begin{tabular}{|c|} 
alunos,profs.,pais,(pesq.) / \\
Hierárquica (pais: Cooperação)
\end{tabular} \\
\hline 13 & $2^{\circ}$ & $M, L P$ & $\begin{array}{l}\text { leitura textos e } \\
\text { situações- } \\
\text { problema }\end{array}$ & $\begin{array}{l}\text { livros infantis, tesoura, } \\
\text { papel, cola etc }\end{array}$ & $\begin{array}{c}\text { alunos,prof.,pesq. / } \\
\text { Hierárquica }\end{array}$ \\
\hline 14 & $4^{\circ}$ & $\begin{array}{c}\text { LP,M,Mus,Art,ES, } \\
\text { C }\end{array}$ & Projeto & $\begin{array}{c}\text { papel, régua, material } \\
\text { para cenário etc }\end{array}$ & $\begin{array}{c}\text { alunos, profs.,pais / } \\
\text { Parceria (pais: Cooperação) }\end{array}$ \\
\hline
\end{tabular}

Legenda das disciplinas: LP: Língua Portuguesa; ES: Estudos Sociais; M: Matemática; C: Ciêncicias; EF: Educação Física; Art: Educação Artística; A: Artes; Fon: Fonoaudiologia; EA: Educação Ambiental, R: Religião; Mus: Música; Fonte: Banco eletrônico de Teses e Dissertações da CAPES (http://www.periodicos.capes.gov.br/portugues/index.jsp), acesso em 26/9/2005.

\footnotetext{
A distribuição das pesquisas quanto aos aspectos curriculares está indicada no Quadro 3.

O descritor nível de inserção curricular evidenciou que a maioria dos trabalhos realiza práticas pedagógicas de natureza curricular, o que denota a articulação dessas com o currículo escolar, com o planejamento das disciplinas e com o projeto político pedagógico das escolas. São ações que acontecem no turno regular de aulas e se integram aos planejamentos regulares das disciplinas. Os demais trabalhos são de natureza extracurricular, nos quais as práticas ocorrem de modo complementar ao planejamento de
} 
ensino e algumas delas sem articulação nenhuma com os planejamentos regulares das disciplinas. Isso de certo modo nos alerta para que intervenções interdisciplinares pontuais de natureza extracurricular pouco contribuem para o exercício efetivo de práticas interdisciplinares na escola, pois tão logo se encerra o trabalho proposto, essa prática é deixada de lado, voltando a ser assumida pela escola e seus educadores a ação pedagógica tradicional. Há que se pensar sobre essa evidência como fonte de reflexão sobre as condições educacionais atuais na sua mais ampla manifestação.

QUADRO 3 - Distribuição das 14 Pesquisas sobre Práticas Pluri ou Interdisciplinares por Nível de Inserção Curricular e Nível de Integração Disciplinar

\begin{tabular}{|c|c|c|c|}
\hline Doc. & Inserção Curricular & Referencial Teórico-Metodológico & Integração Disciplinar \\
\hline 1 & Curricular & Tradicional & Pluridisciplinar \\
\hline 2 & Extracurricular & Sociocultural & Interdisciplinar \\
\hline 3 & Extracurricular & Sociocultural & Interdisciplinar \\
\hline 4 & Curricular & Humanista & pluridisciplinar \\
\hline 5 & Extracurricular & Sociocultural & pluridisciplinar \\
\hline 6 & Extracurricular & Sognitivista & interdisciplinar \\
\hline 7 & Extracurricular & Sociocultural & interdisciplinar \\
\hline 8 & Curricular & Sociocultural & interdisciplinar \\
\hline 9 & Curricular & pedagogia progressista & pluridisciplinar \\
\hline 10 & Curricular & pedagogia crítica & interdisciplinar \\
\hline 11 & Curricular & sociocult./socioconstrutivista & pluridisciplinar \\
\hline 12 & Extracurricular & Sociocultural & interdisciplinar \\
\hline 13 & Curricular & Humanista & interdisciplinar \\
\hline 14 & Curricular & CAPES, & \\
\hline
\end{tabular}

Fonte: Banco eletrônico de Teses e Dissertações da CAPES,

(http://www.periodicos.capes.gov.br/portugues/index.js), acesso em 26/9/2005.

Quanto ao descritor nível de integração disciplinar, 09 documentos trataram de prática pedagógica interdisciplinar; os demais nos possibilitaram vislumbrar alguns ensaios de ação pedagógica interdisciplinar, sendo, portanto, classificados como pluridisciplinares (05 trabalhos).

O referencial metodológico revelou que 07 trabalhos adotam a abordagem sóciocultural, 02 se debruçam sobre a linha humanista, 02 documentos estão pautados na abordagem sócio-construtivista. Segue 01 trabalho representativo de cada linha: cognitivista piagetiana; pedagogia crítica; pedagogia progressista; pedagogia tradicional. Denotamos, a grosso modo, forte tendência na consideração do aluno e suas concepções na relação com a apropriação de novos conhecimentos, o que corrobora com a perspectiva interdisciplinar. Observamos ainda que o conjunto de 14 documentos é concordante quanto a uma prática pedagógica escolar voltada para a realidade e interesse dos estudantes. Alguns documentos ressaltam a presença da ludicidade na ação pedagógica como indispensável para que a aprendizagem ocorra, como também valorizam que no processo de construção do conhecimento sejam considerados os conhecimentos prévios dos estudantes.

Outro ponto de que tratam os autores é a necessidade de revisão dos tempos escolares para se trabalhar com os alunos, e que as reuniões pedagógicas devem ocorrer de modo horizontal e democrático entre as pessoas envolvidas para que se discutam, reflitam e avaliem as ações educativas e o processo de aprendizagem dos estudantes. Além 
disso, o domínio de conteúdo comparece como um item importante para que o professor se sinta seguro em trabalhar com as diferentes disciplinas.

Notamos que a maioria das práticas interdisciplinares ocorre por meio de projetos ou estudos do meio e que as estratégias de ensino utilizadas decorrem de temas geradores que versam sobre a problemática da vida escolar ou da cotidianidade dos estudantes.

As visitas externas, quando realizadas, são previstas no planejamento do professor e o entorno da escola também é utilizado como ambiente favorecedor da prática interdisciplinar.

Alguns trabalhos trazem o foco de conteúdo para a formação de professores em educação ambiental; outros se debruçam na formação de professores em geral. Encontramos ainda pesquisas que têm como temática necessidades outras como: problemas de rendimento escolar e indisciplina de alunos; propostas que surgem dos próprios pesquisadores ou, ainda, um misto de interesse do pesquisador e das necessidades da escola.

\section{Considerações Finais}

Com essa pesquisa, propusemo-nos a conhecer algumas questões relacionadas às práticas pedagógicas interdisciplinares nos anos iniciais do ensino fundamental: como essas práticas se implementam; como se constituem; em que contexto didático acontecem; como se apresentam no planejamento de ensino do professor; se estabelecem relações integradas e colaborativas entre duas ou mais disciplinas; se focalizam outras áreas de conhecimento não presentes no currículo dos anos iniciais; quais as possibilidades e dificuldades de se realizar práticas interdisciplinares; quais as contribuições que essa produção acadêmica oferecem para a educação escolar.

Para isso, analisamos o conjunto de teses e dissertações que tratam de práticas interdisciplinares nos anos iniciais do ensino fundamental, defendidas no Brasil num intervalo de 18 anos, no período de 1987 a 2005.

Durante todo o processo de levantamento de dados, pudemos observar que nem sempre os resumos das dissertações e teses oferecem a clareza necessária para uma seleção adequada do material a ser analisado. Encontramos resumos muito curtos e lacônicos; com falta de clareza quanto às partes essenciais e relevantes da pesquisa; ou, ainda, que apresentam certa confusão entre nível de propósito e o que de fato foi realizado na pesquisa. Cabe um alerta para o cuidado que deve ser dispensado aos resumos das dissertações e teses, pois esses muitas vezes são fonte inicial de dados para outras pesquisas, devem ser fonte fidedigna dos trabalhos realizados, além de ser o recurso primordial para a ampla comunicação e divulgação do trabalho acadêmico.

Das 14 pesquisas que consideramos tratarem de fato de prática pedagógica pluri ou interdisciplinar nos anos iniciais, observamos que essas práticas têm algumas características em comum. Realizam ações através de estudos do meio ou projetos temáticos de investigação, geralmente decorrentes de temas geradores. As ações também estão pautadas na vida cotidiana dos alunos, impregnadas por um ensino que promove o interesse por aprender, num contexto voltado para uma noção totalizante do estudo que está sendo realizado.

Percebemos com clareza a presença de aspectos democráticos e dialógicos presentes nas reuniões pedagógicas e no exercício de avaliação, onde é valorizado o 
questionamento, o diálogo, a cooperação e a busca pela solução de problemas, fatores considerados essenciais pelos pesquisadores para que a prática interdisciplinar se realize.

Notamos que a prática interdisciplinar nas séries iniciais é possível de ser realizada em qualquer contexto escolar, desde que sejam respeitados alguns aspectos essenciais como: realização de reuniões de caráter democrático e horizontal; não hierarquia entre as disciplinas e entre os profissionais envolvidos nessa ação; a existência de um processo avaliativo constante pautado na reflexão sobre a ação; a busca pelo domínio de conteúdo; disposição dos profissionais para ousar quanto ao método de ensino; concepção do conhecimento na sua totalidade de modo inter-relacionado entre a vida, o conhecimento produzido pela humanidade e o desejo de aprender.

Entendemos, por fim, que um projeto interdisciplinar dificilmente conseguirá se estabelecer através de uma ação imposta, a qual desconsidere a dimensão humana do sujeito que irá desencadeá-la junto aos estudantes. Para a prática interdisciplinar se efetivar é necessário que as pessoas envolvidas nesse processo concebam o conhecimento na sua totalidade, entendam-se e sintam-se interdisciplinares. A compreensão do interdisciplinar requer não somente conhecimento sobre essa temática, ou o simples entendimento do intercâmbio entre as disciplinas ou ainda que ela se desenvolva no interior de uma única disciplina, mas exige um envolvimento pessoal com essa questão tanto do ponto de vista epistemológico, como pedagógico e filosófico do sujeito que nela se insere.

Como contribuição para novas investigações sobre a temática interdisciplinar, sugerimos, além da intensificação das pesquisas que apresentem estudos sobre práticas interdisciplinares nos anos iniciais do ensino fundamental, outras que se dediquem a estudar a prática interdisciplinar na Educação Ambiental, as práticas interdisciplinares abrangendo a formação inicial ou continuada de professores ou ainda a concepção que professores e educadores em geral têm sobre interdisciplinaridade.

\section{Referências}

DESCARTES. René. Discurso sobre o Método. Trad. de Torrieri Guimarães. São Paulo: Hemus, 1975. $100 \mathrm{p}$.

FAZENDA, Ivani C. A. Interdisciplinaridade: um projeto em parceria. São Paulo: Loyola, 1995. 174 p.

FERREIRA, Norma Sandra de A. As pesquisas denominadas "Estado da Arte". Revista Educação \& Sociedade, Campinas, v. 23, n. 79, p. 1-16, ago. 2002.

HECKHAUSEN, Heinz. Disciplina e interdisciplinaridade. In: POMBO, Olga et al. (Orgs.). Interdisciplinaridade - Antologia. Porto: Campo das Letras. 2006. p. 79-90.

JAPIASSU, Hilton. Interdisciplinaridade e patologia do saber. Rio de Janeiro: Imago, 1976. 220 p.

MEGID NETO, Jorge. Tendências da pesquisa acadêmica sobre o ensino de Ciências no nível fundamental. 1999. 144 f. Tese (Doutorado em Educação) - Faculdade de Educação, Universidade Estadual de Campinas, Campinas, 1999.

PIAGET, J. L'Epistemologie des Relations Interdisciplinaires. L'Interdisciplinaireté: problèmes d'enseignement et de recherche dans les universités. Centre pour la recherche et l'innovation dans I'enseignement. Paris: OCDE, 1972. p. 131- 144.

SOARES, Magda. Alfabetização no Brasil: o estado do conhecimento. Brasília: INEP/MEC, 1989. 151 p. 
TEIXEIRA, Paulo M. M.; MEGID NETO, Jorge. Investigando a pesquisa educacional: um estudo enfocando dissertações e teses sobre o ensino de Biologia no Brasil. Investigações em Ensino de Ciências, Porto Alegre, v. 11, n. 2. 2006.

ZOBÓLI, Graziela Bernardi. Um projeto de integração à luz da interdisciplinaridade. 1992. $71 \mathrm{f}$. Dissertação (Mestrado em Educação) - Faculdade de Educação, PUC-SP, São Paulo, 1992. 


\section{Apêndice}

\section{Referências das 14 Teses e Dissertações sobre Práticas Pedagógicas Pluri ou Interdisciplinares nas Séries Iniciais do Ensino Fundamental}

Doc. 01 - ARAUJO, Maria Carmem de C. Silva. A prática pedagógica do professor alfabetizador bem sucedido das camadas populares. São Paulo, PUC-SP, 1993. 139 p. Dissertação de Mestrado. (Orientador: Antonio Chizzotti).

Doc. 02 - ASSUNÇÃO, Washington Luiz. A educação ambiental como um processo interdisciplinar: uma experiência com a coleta seletiva de lixo na Escola Estadual Joaquim Saraiva. Uberlândia, UFU, 1995. 222 p. Dissertação de Mestrado. (Orientador: Regina Célia de Santis Feltran).

Doc. 03 - BRAUNA, Rita de Cássia de Alcantara. Formação continuada em Ciências de professores do ensino fundamental numa perspectiva interdisciplinar e as possibilidades de mudanças. São Paulo, USP, 2000. 202 p. Tese de Doutorado. (Orientador: Yassuko Hosoume).

Doc. 04 - DANTAS, Joana D'Arc de Sousa. A ação pedagógica do professor e a aprendizagem do aluno: um trabalho cooperativo. Rio Grande do Norte, UFRN, 2001. 200 p. Tese de Doutorado. (Orientador: Neide Varela Santiago).

Doc. 05 - FRUTUOSO, Maria Núbia Medeiros de Araújo. A interdisciplinaridade no ensino. Educação, Recife, UFPE, 2002. 115 p. Dissertação de Mestrado. (Orientador: Celi Nelza Zulke Taffarel).

Doc. 06 - GOING, Luana Carramillo. Contos para "Escrever-se": alfabetização por meio de contos de fadas folclóricos com base em Jean Piaget e Bruno Bettelhein. São Paulo, Universidade Metodista de São Paulo, 1994. Dissertação de Mestrado. (Orientador: Eda Marconi Custódio).

Doc. 07 - GONÇALVES, Francisca dos Santos. Vida, trabalho e conhecimento: metodologia para a elaboração coletiva e interdisciplinar do conhecimento fundado no trabalho como princípio educativo - uma contribuição para a formação do professor. São Paulo, USP-FE, 1995. 2v. 443p. Tese de Doutorado (Orientador: Dirceu Ricci Carvalho).

Doc. 08 - HOFFMANN, Vera Kern. Uma proposta interdisciplinar de educação nas primeiras quatro séries do ensino fundamental, na perspectiva do desenvolvimento sustentável. Universidade Luterana do Brasil - ULBRA, 2003. 95 p. Dissertação de Mestrado. (Orientador: Claudia Lisete Oliveira Groenwald).

Doc. 09 - LIMA, Maria de Lourdes. Sensibilização ambiental no processo educativo: o tema dos resíduos sólidos urbanos no Programa Curricular de 1 a Série do Ensino Fundamental. Maringá, UEM, 2003. 170 p. Dissertação de Mestrado. (Orientador Elza Yasuko Passini).

Doc. 10 - MELLO, Alexandre Moraes de. Educação Física integrada à alfabetização (EFIALFA) - um método específico de ensino para Educação Física nas turmas de alfabetização. São Paulo, Educação, USP, 1998. 186 p. Tese de Doutorado. (Orientador Marieta Lúcia Machado Nicolau).

Doc. 11 - POLENZ, Tamara. Educação, interdisciplinaridade e ação comunicativa: Uma vivência na realidade da escola. Educação, UNISINOS, 1997. 149 p. Dissertação de Mestrado. (Orientador: Maria Augusta Salin Gonçalves).

Doc. 12 - SANTOS, Maria José Albuquerque. Um estudo de interdisciplinaridade: vivências numa quarta série do 10 grau. São Paulo, Educação, Universidade Estadual Paulista Julio de Mesquita Filho, 1998. 220 p. Dissertação de Mestrado. (Orientador: Helena Faria De Barros).

Doc. 13 - SILVA, Adelmo Carvalho da. Matemática e literatura infantil: um estudo sobre a formação do conceito de multiplicação. João Pessoa, Educação, UFPB, 2003. 192 p. Dissertação de Mestrado. (Orientador: Rogéria Gaudêncio do Rego).

Doc. 14 - WARSCHAUER, Cecília. A roda e o registro: caminhos para a parceria entre professor e aluno na construção dos conhecimentos. São Paulo: Educação, USP, 1991. 218 p. Dissertação de Mestrado. (Orientador: Nympha Aparecida Al Sipavicius). 